\title{
Algorithmic regulation and the global default: Shifting norms in Internet technology
}

\author{
Ben Wagner \\ Centre for Internet \& Human Rights, European University Viadrina, \\ bwagner@europa-uni.de \\ DOI: http://dx.doi.org/10.5324/eip.v10i1.1961 \\ (cc) BY 1 This is an open access article distributed under the terms of the Creative Commons Attribution \\ 4.0 International License, which permits unrestricted use, distribution, and reproduction in any \\ medium, provided the original author and source are credited.
}

The world we inhabit is surrounded by 'coded objects', from credit cards to airplanes to telephones (Kitchin \& Dodge, 2011). Sadly, the governance mechanisms of many of these technologies are only poorly understood, leading to the common premise that such technologies are 'neutral' (Brey, 2005; Winner, 1980), thereby obscuring normative and power-related consequences of their design (Bauman et al., 2014; Denardis, 2012). In order to unpack supposedly neutral technologies, the following paper will look at one key question around the technologies used on the global Internet: how are the algorithms embedded in software governed? The paper will look in detail at the question of algorithmic governance before turning to one specific example: content regulatory regimes. Finally, it will focus on drawing conclusions in understanding the normative frameworks embedded in technological systems.

Keywords: algorithms, governance, freedom of expression, technology \& society, ethics of technology

\section{Governing algorithms}

The attempts by public regulators to influence the mathematical algorithms present within automated software programs constitute one particularly interesting Internet governance practice. The 2015 scandal around the software algorithms used to manipulate emissions in Volkswagen cars is one obvious example of the challenges related to their governance (Burki, 2015; Schiermeier, 2015). This is particularly clear in this case, as the regulators of these cars did not even have access to the actual software embedded in the cars.

In the context of this article, algorithms represent a large part of the decisionmaking processes that are termed here 'first-order rules.' These are automated decision-making processes, governed by algorithms of varying degrees of complexity. They are also the foundation of many rules and regulations related to information control. In its simplest form, a Facebook algorithm filters large amounts of content, such as user posts, to try and decide whether the content is permissible. The algorithm may, for example, be set to filter out flesh-coloured images, those that contain swear words or those that come from a certain part of the world and repeatedly ask for a bank account. However, the algorithm can also be set to learn from human decisions, replicating their decision-making processes, 
operational practices, stereotypes, habits and prejudices (Pariser, 2011; Sunstein, 2007). For example, "computational hiring systems have found that low commute time corresponds to low turnover" (Zeynep Tufekci, York, Wagner, \& Kaltheuner, 2015), which in turn correlates strongly with both class and race. It has also been suggested that in "the case of extremist or terrorist content the recommender system can keep 'recommending' further extremist material once a user has watched just one" (Zeynep Tufekci et al., 2015), helping to strengthen the creation of "ideological bubbles" (O'Callaghan, Greene, Conway, Carthy, \& Cunningham, 2014).

Of course, machine learning typically uses a large sampling of individuals, in the hope that individual biases wash out over time. However, in these dimensions a level of complexity sets in which becomes difficult to manage. The reason is that these automated systems have moved beyond simple variablebased responses, and are instead responding to their surrounding based on a 'machine learning' process. As it is often too costly to stop this learning process, case-by-case filters are occasionally introduced in order to modify

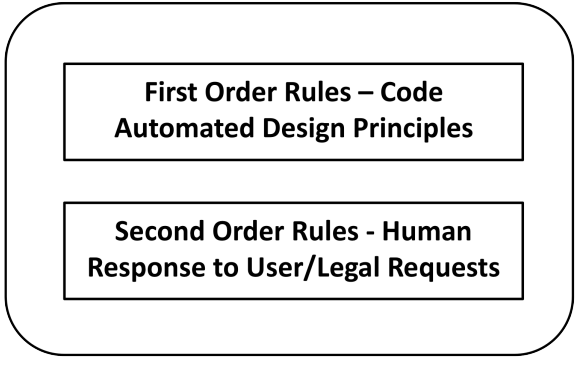

Figure 1: First- and second-order regulatory rules the prima facie responses of the system.

Thus, a distinction needs to be made between first-order rules, which are automated in computer code, and second-order rules, which involve individual changes to the output created by these algorithms. A second-order rule would remove some of the outputs of the algorithm that are unwanted, for example limiting individual Google search results by filtering out certain images or keywords. A typical example here is the Max Mosley case, where a judge required Google to remove certain specific outputs from its search engine results (Stanley, 2011). The algorithm itself did not, however, need to be changed, rather its results simply needed to be limited.

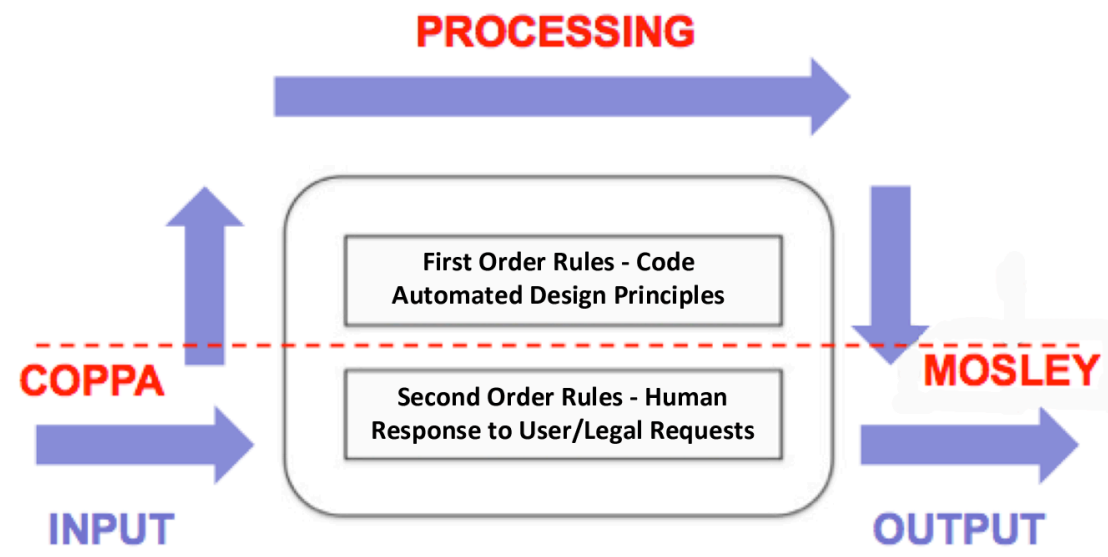

Figure 2: First- and second-order rules in practice

Similar things can be said about the COPPA regulatory framework, which attempts to protect minors from advertising and thus limits the data that private companies can legally collect from individuals (Wagner, 2013). Both the Max Mosley court decision and COPPA limit the algorithmic decision-making input and 
output, but not the processing of data conducted by the algorithm itself. In the manner used above, COPPA and Mosley are both second-order rules in that they limit data inputs or outputs of an algorithm without actually changing the algorithm itself.

Actually tweaking the variables of the data processing algorithm and changing the way the machine learns are tasks reserved for a select few engineers, who optimise and experiment on the algorithms that Google or Facebook use globally. Although public regulators have not yet been able to influence Google algorithms, the FTC and EU investigation into 'Search neutrality' revolves precisely around this question (Manne \& Wright, 2012; Petit, 2012; van Hoboken, 2012). Can an Internet search monopoly be compelled to change not only its second-order principles, but its first-order principles as well? Can regulators require Google to force its algorithm to act in certain ways towards certain competing sites? This would in effect require the public regulators to have access to the algorithm, employ individuals capable of understanding its properties and be able to modify it effectively in the interests of the public. While it is not entirely clear what the public interest is in this context, parliaments, courts, private companies and public authorities are vying to define it (Bennett, 2010; EDPS, 2016; Schulz, 2016; Stanley, 2011).

One area where algorithmic regulation has already begun to be discussed is the area of financial regulation. Due to the increasing use of automated high-speed trading systems and their potentially destabilising effect on financial markets, regulators have begun to demand both transparency over high-speed trading algorithms and the ability to modify these algorithms if they are considered unstable (Steinbrück, 2012). A policy paper written by Peer Steinbrück, the social democratic (SPD) candidate for German chancellor in 2013, recommends the following procedures to deal with high-speed financial trading systems:

The core of an effective regulation needs to be a public certification system not just for trading companies, but for the trading algorithms themselves. This certification system will first analyse the algorithm based on its trading strategy: dangerous trading strategies must be banned! Moreover the algorithms will have to undergo a stress test to ascertain their stability (Steinbrück, 2012, translation by the author).

This shift away from regulating the human beings that are responsible for developing the algorithmic trading system and towards the algorithms themselves is a particularly interesting development. It assumes that it is possible to objectively predict the responses of certain algorithms to different types of situations and that the assessment of such algorithms is more effective than the assessment of the people developing it. This reflects a shift similar to the one noted above of increasingly specific governance practices. Faced with an increasing level of complexity and their own regulators' lack of leverage, public actors are responding with ever more precise and finely tuned governance practices to get to the heart of the systems they are trying to gain control over.

The high level of precision in governance that is possible in turn gives the regulator a great deal of leverage with only relatively small changes to the regulatory mechanism, plus all of the advantages of using software code which lie in its automation and scalability, i.e. that the cost of repetition is low or negligible and in 
most cases can quickly be used not just for a small number but can also be quickly and easily replicated up to a large number of repetitions.

For certain types of economic and even socio-political regulation, this form of algorithmic regulation may be quite effective, insofar as it modifies existing market practices which are themselves already based on algorithms. However, such regulation relies on oligopolistic or monopolistic markets and is extremely invasive for the companies being regulated, which are being asked to modify what can be considered the core of their business. It is also likely very difficult for all but the largest countries to compel companies to modify the first-order rules which govern their algorithms.

\section{Content regulatory regimes}

On 29 June 2015 the Counter Extremism Project (CEP) opened its offices in Brussels. A highly influential and swiftly expanding group, it called for "[s]ocial media companies that don't remove extremist material from their websites [to] face sanctions" (Stupp, 2015). This organisation includes many of the hallmarks of how content on the global Internet is governed: a government-funded non-profit with the ability to exert considerable pressure on private sector actors through expertise in a specific subject area. The following section will attempt to explain how such organisations come about and result in the emergence of a "regime of competence" (Wenger, 2009). It will be argued that communities of practice construct a global "regime of competence" (Wenger, 2009) which enables them to govern in these areas. This regime of competence has certain attributes and actor constellations that will be discussed in order to understand how the overall regime is governed.

This leads to what is being discussed here as the global default. The 'global default' is a global regime of competence that defines permissible online content. While parts of the regime draw from public regulation and even state legislation, the vast majority of the regime is based on private norms and practices. The regime itself is embedded within agreements between private sector actors who are responsible for definition, management and implementation of the regime. Insofar as the public sector participates in this system, the institutions have adapted to fit this model, relying primarily on private sector notice and takedown procedures for enforcement. While all of this of course takes place under the shadow of state hierarchy (Héritier \& Eckert, 2008), the extent of public sector coercion is typically relatively limited.

In order to make these regimes performative, many of the private sector actors embed their norms in technology. Thus, users of online search engines are likely aware of the many different lists used to filter content out of their searches. One such list is provided by the Internet Watch Foundation (IWF) and automatically implemented by most large online search engines. This leads the small German quasi-public NGO Jugendschutz.Net to set the global standard on pictures of children in provocative sexual poses ('Posendarstellungen'), the U.S. corporation Facebook to set the global standard for speech regulation in regard to nudity in social spaces online and the British private sector initiative, the IWF, to provide the foundational definition of child sexual abuse material, which is blocked not just in the UK, but by online service providers across the world. 
Similar things can be said for the role of the U.S. CDA Supreme Court decision or the role of waves of UK governmental coercion on IWF policy (Goldsmith \& Wu, 2006; Nussbaum, 2011), both of which heavily impacted the global default of speech. Strangely, however, perhaps the most important piece of legislation influencing speech online is COPPA (Wagner, 2013), which defines the age at which corporations can advertise to human beings. Indeed, much of the relevance of these public sector actors depends on the predominance of private companies. The influence of COPPA in the U.S., as well as the influence of the British government, would be far less if large quasi-monopolies like Google or Facebook did not exist. What has been called "U.S. Free Speech Imperialism" (Rosen, 2013) not only has effects beyond the U.S., but is also influenced by actors outside the U.S. At the same time, the nature of the global default of speech is not solely influenced by factors promoting speech - such as the U.S. First Amendment.

Notably, this form of market dominance exists in other global regulatory regimes as well. In regard to the governance of global supply chains, for example, the "power of such 'parameter-setting' firms, such as Shimano in bicycles and Applied Materials in semiconductors, is not exerted through explicit coordination, but through their market dominance in key components and technologies" (Gereffi, Humphrey, \& Sturgeon, 2005, p. 98). As with large Internet companies, market dominance translates into an informal private governance regime of the respective area, enabling the creation of a private regulatory regime.

In the area of financial service regulation, Cafaggi (2011) argues that while some of the regulation in the financial services area is industry driven, such as the "International Accounting Standards Board (IASB)," (Cafaggi, 2011, p. 36) there are also examples such as the "International Swaps and Derivatives Association (ISDA)" (Cafaggi, 2011, p. 36), which follow a multi-stakeholder model of governance, although other competing forms of governance also exist. Interestingly, the nature of the ISDA's governance is disputed within academia, with other authors beyond Cafaggi referring to ISDA simply as "the largest global financial trade association" (Biggins \& Scott, 2012, p. 324), whose "lobbying influence cannot be downplayed" (Biggins \& Scott, 2012, p. 323).

Thus it seems reasonable to suggest that there are similar elements of governance in other domains than Internet governance. On the one hand, elements of the 'global default' and its private governance regime share some similarities with global supply chains, where informal private regulatory regimes are created through market dominance. On the other hand, there are some similarities to global financial regulation, where the nature of multi-stakeholder governance is contested.

\section{Social norms embedded in technology}

What should be evident from the discussion above is that the norms embedded in technology are not transparent to the vast majority of their users. These norms are also not static, rather they are objects of persistent and on-going struggles (Denardis, 2012). This is particularly the case regarding connected digital technologies that can be and are being constantly changed, updated and modified. This malleability makes them particularly attractive for numerous actors who wish to govern through them. 
Importantly, while the social norms embedded in technology are evidently influenced by legal regimes, they are not the same as the relevant legal regimes and often diverge from them in numerous ways. As discussed, Facebook's rules on Free expression have little to do with the First Amendment of the United States Constitution or indeed the legal framework for freedom of expression of any country in the world. Likewise, algorithms used in the global search engine market evidently pose considerable challenges to competition law and are thus currently under investigation (Kovacevich, 2009; Pollock, 2009).

However, the danger in looking at the normative frameworks embedded in technology simply as 'good' or 'bad' algorithms, is that they are neither. Rather they are products of a socio-technical process that can only be understood by looking both at technology and human interaction with it (Brey, 2005). Algorithms, like any other technology, can thus be considered "biased but ambivalent" (McCarthy, 2011, p. 90).

What can strongly be suggested, however, is that technologies are key loci of control where power is distributed and redistributed (Klang, 2006; Z Tufekci, 2015). Thus, understanding which norms are embedded in technology also assists in understanding the power structures that govern the production and usage of technology. Although this process of socio-technical construction remains relatively opaque to the general public, it is becoming increasingly influential in a variety of systems within society.

In this context, it is necessary to return to the distinction between first- and second-order rules. The reason this distinction is so important is that while secondorder rules are overwhelmingly non-automatable and require repeated input for each individual case, first-order rules are necessarily automatable as they are part of automated technical processes. These are particularly attractive to governance regulators and companies alike as a form of regulation since they scale, an important criterion for effective governance of any digital technology. Without scalability, regulators are left to constantly repeat the same individual case-by-case challenges of systems, rather than being able to influence

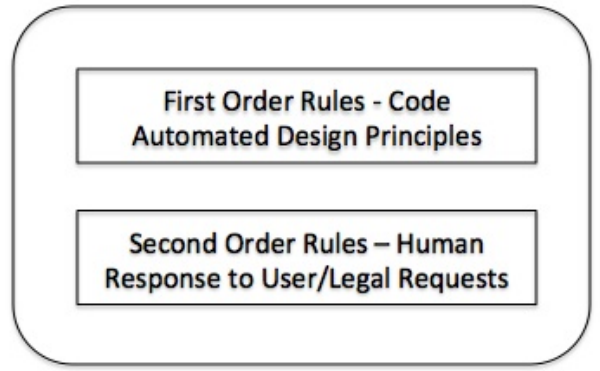

Figure 1: First- and second-order regulatory rules the system as a whole.

Indeed, in many cases the governing bodies involved do not even have access to key algorithms, as the 2015 scandal around Volkswagen's manipulation of emissions standards within its motors suggests. By simply refusing or failing to provide key software to relevant automobile regulators around the world, Volkswagen was able to sell cars that did not meet relevant government emissions standards. This example clearly demonstrates the power embedded in algorithms and the attractiveness of a scalable governance mechanism. It also clearly suggests that not only is technology not neutral, it represents a multi-layered battleground of existing struggles around social norms (Tawil-Souri, 2015). Thus, technological infrastructure itself reflects many of the key power struggles of the past decades, whether these are related to the future of the environment and emissions rates of cars, the appropriate regulation of the stock market and financial trading or the 
control of Internet content. In all of these cases, technology is neither neutral nor good or evil, but simply reflects existing power structures and struggles that through malleable technology directly impact the life-world of human beings.

\section{References}

Bauman, Z., Bigo, D., Esteves, P., Guild, E., Jabri, V., Lyon, D., \& Walker, R. B. J. (2014). After Snowden: Rethinking the Impact of Surveillance. International Political Sociology, 8(2), 121-144. http://dx.doi.org/10.1111/ips.12048

Bennett, B. (2010). YouTube is letting users decide on terrorism-related videos. Los Angeles Times. Retrieved February 11, 2012, from http://articles.latimes.com /2010/dec/12/nation/la-na-youtube-terror-20101213

Biggins, J., \& Scott, C. (2012). Public-Private Relations in a Transnational Private Regulatory Regime: ISDA, the State and OTC Derivatives Market Reform. European Business Organization Law Review, 13(03), 309-346. http://dx.doi.org/10.1017/S1566752912000262

Brey, P. (2005). Artifacts as social agents. In H. Harbers (Ed.), Inside the politics of technology: Agency and normativity in the co-production of technology and society (pp. 61-84). Amsterdam University Press.

Burki, T. K. Diesel cars and health: the Volkswagen emissions scandal. The Lancet Respiratory Medicine, 3(11), 838-839. http://dx.doi.org/10.1016/S22132600(15)00409-9.

Cafaggi, F. (2011). New Foundations of Transnational Private Regulation. Journal of Law and Society, 38(1), 20-49. http://dx.doi.org/10.1111/j.14676478.2011.00533.x

Denardis, L. (2012). Hidden Levers of Internet Control. Information, Communication \& Society, 15(5), 37-41. http://dx.doi.org/10.1080/ 1369118x.2012.659199

EDPS. (2016). EDPS starts work on a New Digital Ethics. Brussels, Belgium.

Gereffi, G., Humphrey, J., \& Sturgeon, T. (2005). The governance of global value chains. Review of International Political Economy, 12(1), 78-104. http://dx.doi.org/10.1080/09692290500049805

Goldsmith, J. L., \& Wu, T. (2006). Who controls the Internet? illusions of a borderless world. Oxford University Press.

Héritier, A., \& Eckert, S. (2008). New Modes of Governance in the Shadow of Hierarchy: Self-regulation by Industry in Europe. Journal of Public Policy, 28(01), 89-111. http://dx.doi.org/10.1017/S0143814X08000809

Kanter, J. and Streitfeld, D. (2012, May 21). Europe weighs Antitrust Case against Google, urging search changes. The New York Times. Retrieved 16 April 2015, from http://www.nytimes.com/2012/05/22/business/global/europe-warnsgoogle-over-antitrust.html?_r=0

Kitchin, R., \& Dodge, M. (2011). Code/space software and everyday life. MIT Press. 
Klang, M. (2006). Disruptive technology: effects of technology regulation on democracy. Göteborg: Department of Applied Information Technology, Göteborg University.

Kovacevich, A. (2009). Google Public Policy Blog: Google's approach to competition. Google Public Policy Blog. Retrieved October 27, 2012, from http://googlepublicpolicy.blogspot.de/2009/05/googles-approach-tocompetition.html

Manne, G., \& Wright, J. (2012). If Search Neutrality is the Answer, What's the Question. Colum. Bus. L. Rev.

McCarthy, D. R. (2011, January). Open Networks and the Open Door: American Foreign Policy and the Narration of the Internet. Foreign Policy Analysis. http://dx.doi.org/10.1111/j.1743-8594.2010.00124.x

Nussbaum, M. C. (2011). Objectification and Internet Misogyny. In S. Levmore \& M. C. Nussbaum (Eds.), The Offensive Internet: Privacy, Speech, and Reputation. Harvard University Press.

O’Callaghan, D., Greene, D., Conway, M., Carthy, J., \& Cunningham, P. (2014). Down the (White) Rabbit Hole: The Extreme Right and Online Recommender Systems. Social Science Computer Review, 33(4), 459-478. http://dx.doi.org/ $10.1177 / 0894439314555329$

Pariser, E. (2011). The filter bubble: what the Internet is hiding from you. New York: Penguin Press.

Pollock, R. (2009). Is Google the next Microsoft?: competition, welfare and regulation in internet search. Cambridge: University of Cambridge Faculty of Economics.

Rosen, J. (2013). Free Speech on the Internet: Silicon Valley is Making the Rules. New Republic. Retrieved May 9, 2013, from http://www.newrepublic.com/ article/113045/free-speech-internet-silicon-valley-making-rules\#

Schiermeier, Q. (2015). The science behind the Volkswagen emissions scandal. Nature News. http://dx.doi.org/10.1038/nature.2015.18426

Schulz, M. (2016). Keynote speech at \#CPDP2016 on Technological, Totalitarianism, Politics and Democracy. European Parliament. Retrieved February 12, 2016, from http://www.europarl.europa.eu/thepresident/en/press/press_release_speeches/speeches/speeches-2016/speeches2016-january/html/keynote-speech-at--cpdp2016-on-technological-totalitarianism--politics-and-democracy

Stanley, J. (2011). Max Mosley and the English Right to Privacy. Wash. U. Global Stud. L. Rev., 10(3), 641. http://openscholarship.wustl.edu/law_globalstudies/ vol10/iss $3 / 7$

Steinbrück, P. (2012). Vertrauen zurückgewinnen: Ein neuer Anlauf zur Bändigung der Finanzmärkte. Berlin, Germany.

Stupp, C. (2015). Social media watchdog: Twitter is the gateway drug for extremists. EurActiv. Retrieved July 28, 2015, from http://www.euractiv.com/section/justicehome-affairs/news/social-media-watchdog-twitter-is-the-gateway-drug-for-extremists/ 
Sunstein, C. (2007). Republic.com 2.0. Princeton: Princeton University Press.

Tawil-Souri, H. (2015). Cellular Borders: Dis/Connecting Phone Calls in IsraelPalestine. In L. Parks \& N. Starosielski (Eds.), Signal Traffic: Critical Studies of Media Infrastructures (pp. 157-182).

Tufekci, Z. (2015). Algorithms in our Midst: Information, Power and Choice when Software is Everywhere. Proceedings of the 18th ACM Conference on Computer (p. 1918). http://dx.doi.org/10.1145/2675133.2697079

Tufekci, Z., York, J. C., Wagner, B., \& Kaltheuner, F. (2015). The Ethics of Algorithms: from radical content to self-driving cars. Berlin, Germany.

van Hoboken, J. V. J. (2012). Search Engine Freedom: On the implications of the right to freedom of expression for the legal governance of Web search engines. University of Amsterdam (UvA). http://hdl.handle.net/11245/1.392066

Wagner, B. (2013). Governing Internet Expression: how public and private regulation shape expression governance. Journal of Information Technology \& Politics, 10(3), 389-403. http://dx.doi.org/10.1080/19331681.2013.799051

Wenger, E. (2010). Communities of practice and social learning systems: the career of a concept. In Blackmore, C. (ed.), Social learning systems and communities of practice (pp. 179-198). Springer London. http://dx.doi.org/10.1007/978-184996-133-2_11

Winner, L. (1980). Do Artifacts Have Politics? Daedalus, 109(1), 121-136. Retrieved from http://www.jstor.org/stable/20024652 